Hans MaES

\title{
ART OR PORN: \\ CLEAR DIVISION OR FALSE DILEMMA?
}

\section{I}

Terrold LeVinson CONVEniently summarizes the main argument of his essay "Erotic Art and Pornographic Pictures" in the following way:

(1) Erotic art consists of images centrally aimed at a certain sort of reception R1.

(2) Pornography consists of images centrally aimed at a certain sort of reception $\mathrm{R} 2$.

(3) R1 essentially involves attention to form/vehicle/medium/ manner, and so entails treating images as in part opaque.

(4) R2 essentially excludes attention to form/vehicle/medium/ manner, and so entails treating images as wholly transparent.

(5) R1 and R2 are incompatible.

(6) Hence, nothing can be both erotic art and pornography; or at the least, nothing can be coherently projected as both erotic art and pornography. ${ }^{1}$

I have argued elsewhere that premises (1) to (5) are problematic, not least in light of Levinson's own views on the definition of art and the nature of depiction. ${ }^{2}$ I now want to focus on the final step of the argument. It is evident that (6) only follows from (1) to (5) if it is assumed that one cannot coherently and successfully aim at two incompatible audience responses. Yet, it seems to me that this assumption is false. One can (coherently and successfully) aim at incompatible audience 
responses, as long as one does not expect these responses to be elicited at the same time, in the same audience, by the same part of the work. Accordingly, it appears not impossible or incoherent at all to create something that qualifies as both art and pornography.

Whether we consider works of art, works of pornography, or cases in the disputed middle ground, what Levinson seems to have overlooked is that most of the representations involved are intended for multiple occasions of reception. They have various different parts (chapters, scenes, etc.) or various intended audiences or deliberately invite the kind of response that can evolve over time. Thus, while the same person cannot at the same time treat the same part of a picture or novel as both opaque and transparent, one can attempt (and succeed) to create work that is treated (A) as transparent in a first phase and as opaque in a later phase; or (B) as transparent by one part of the audience and as opaque by another part of the audience; or $(\mathrm{C})$ in some parts as transparent, in other parts as opaque. To illustrate and further elaborate these three possible scenarios I will present some non-pornographic examples (for pornographic examples, see section III).

(A) It sometimes happens that people first treat images as transparent and only afterwards attend to matters of form/vehicle/medium/ manner-a process that can be anticipated and planned by the artist. The Maltese Falcon (John Huston, 1941) or The Bourne Ultimatum (Paul Greengrass, 2007) may serve as a case in point. In his review of The Bourne Ultimatum the film critic Roger Ebert observes that there are two kinds of long takes: “(1) the kind you're supposed to notice, as in Scorsese's GoodFellas, when the mobster enters the restaurant, and (2) the kind you don't notice, because the action makes them invisible. Both have their purpose: Scorsese wanted to show how the world unfolded before his hero, and Greengrass wants to show the action without interruption to reinforce the illusion it is all actually happening." ${ }^{3}$ Ebert makes a similar remark about the famous 7 minute long shot in The Maltese Falcon: "Was the shot just a stunt? Not at all; most viewers don't notice it, because they're swept along by its flow." Huston's and Greengrass's virtuoso shots belong to the "kind you don't notice" and are not supposed to notice, as both directors want to throw the audience right into the action. Levinson writes of pornographic pictures that "they should present the object of sexual fantasy vividly, and then, as it were, get out of the way" (p. 233). In a sense, this is exactly what Huston and Greengrass are aiming for: to present the unfolding events as vividly as 
possible and then, as it were, get out of the way. In other words, they want the audience to treat the images as transparent. Of course, when seeing the films for a second time, or studying the scenes frame-byframe, one's attention will be drawn to the remarkable formal features and stylistic achievements. There is little doubt that the makers would welcome such detailed film analysis. Like most artists, they want their artistry to be acknowledged and appreciated. As such, these films invite the audience to respond in radically different ways at different times (ignoring and then later attending to formal features).

Why, one could ask, would the same not be possible for pornography? Huston and Greengrass do not want to draw attention to their own virtuosity, at least not immediately, and instead want the audience to be fully immersed in the story. Making this degree of immersion possible typically requires great artistic skill—skill that will invite admiration when successfully applied. In much the same way, I think, one can imagine a pornographic film that, through excellent acting, a truly gripping story, effective use of lighting and sound, succeeds in presenting the objects of sexual fantasy more vividly than ever, being sexually arousing in the first place and inviting the viewer afterwards to contemplate the relationship between the arousal achieved and the means employed to achieve it. Even within the narrow parameters set by Levinson, such a film would qualify as pornographic art.

(B) It can be the aim of the artist that one part of the audience treats the images as transparent while another part of the audience treats them as opaque. Again, films offer good examples. Take Quentin Tarantino's Kill Bill or Death Proof. An argument could be made that these films are pastiches of certain popular genres. On the one hand, they possess many obvious genre markers of kung fu films, slasher films and car chase movies, but on the other hand, they also challenge and stretch the conventions of those genres, exaggerating certain aspects and employing typical narrative or stylistic devices in an extremely self-conscious way. As such they seem to appeal to both the usual consumers of those genre films and to film critics and film buffs. The latter are drawn to Tarantino's films for cinematic reasons, paying close attention to the many subtle references, original dialogues and virtuoso camerawork, usually absent from the typical instances of these genre films. Teenagers, by contrast, unaware of or uninterested in these stylistic aspects, treat his pictures as more or less transparent. They are absorbed by the story and the action or violence depicted, quite oblivious to Tarantino's 
sophisticated recuperation of film history. Thus, films like Kill Bill and Death Proof are perfectly geared towards audiences that ignore matters of form/vehicle/medium/manner and audiences that precisely focus on those features.

If this is possible for the slasher and kung fu genre, then why not for pornography? In fact, Quentin Tarantino has stated in interviews that he would once like to direct a porn movie. If he ever decides to go through with this, and if the result is as "Tarantinesque" as the rest of his oeuvre, we have every reason to suspect that the film will be received in radically different ways by different audiences, and will be regarded as film art and pornography at the same time.

(C) An artist can intend one part of her work to be treated as transparent, while another part of the work is treated as opaque. This is the most straightforward of the three scenarios. Even if we were to subscribe to Levinson's idea that aesthetic experience (R1) and sexual arousal (R2) are mutually exclusive, one could still imagine an author writing a novel with great literary merit, wishing to give her readers aesthetic delight, but also adding one or two sexually explicit and arousing chapters for purely commercial reasons; or a filmmaker who, hoping to create a financially profitable controversy, adds a few pornographic scenes to an arthouse film (this is what Bob Guccione did in the final editing stage of Caligula, making it the highest grossing Penthouse film of all time). Examples of this sort illustrate in yet another way how it is not in the least impossible to aim at two radically different or even conflicting audience responses.

Of course, diverging aims as the ones I have just described, may result in work that lacks coherence. But this need not be the case. Moreover, even if the resulting work is less than coherent, that would only imply that it is not as good a work of art as it could have been (there are many great works of art that are somewhat flawed because of conflicting ambitions within the work). This one deficiency in itself would not justify excluding the work from the realm of art altogether. Yet, that is exactly what Levinson wishes to establish. He does not just say that pornographers produce bad art. Rather, he claims that what pornographers produce has nothing to do with art, that everything they create falls outside of the realm of art. I have tried to show that this claim is fundamentally unwarranted and untenable. 
I turn now to Christy Mag Uidhir's essay "Why Pornography Can't Be Art." Like Levinson, he has chosen a title that leaves no doubt as to where he stands on the issue at hand and with a similar degree of clarity and organization he lays out his argument:

(1) If something is pornography, then that something has the purpose of sexual arousal (of some audience).

(2) If something is pornography, then that something has the purpose of sexual arousal and that purpose is manner inspecific.

(3) If something is art, then if that something has a purpose, then that purpose is manner specific.

(4) If something is art, then if that something has the purpose of sexual arousal, then that purpose is manner specific.

(5) A purpose cannot be both manner specific and manner inspecific.

(6) Therefore, if something is pornography, then it is not art. ${ }^{5}$

For Mag Uidhir, a purpose is manner specific if it is essentially constituted both by an action (or state of affairs) and a manner, such that the purpose is to perform that action (or bring about that state of affairs) in that particular manner. For a purpose to be manner inspecific, by contrast, is simply for it not to be manner specific. In other words, if a purpose is manner inspecific, then failure to bring about the state of affairs in the prescribed manner does not constitute failure to satisfy the purpose.

Mag Uidhir's account has a number of distinct advantages. To begin with, it is entirely value neutral in the sense that it does not appeal to some essential moral or aesthetic value difference to draw the line between the realm of art and the realm of pornography. Furthermore, his account is not based on any robust theories of art or pornography. Mag Uidhir only invokes a limited set of necessary conditions. Given how difficult it has proven in the past to define either what art or what pornography is, this certainly seems a commendable strategy. While Levinson's argument is bogged down by the controversial claim that a work of art's main purpose is to create an aesthetic experience and draw attention to its own formal features, Mag Uidhir's argument does 
not rely on any such substantial claim. Still, regarding the central issue, he aligns himself squarely with Levinson. He, too, thinks that artists or pornographers attempting to produce something that is both art and pornography, in fact attempt the impossible. I hope to show, however, that his argument ultimately fails in the same way that the argument in "Erotic Art and Pornographic Pictures" fails. The conclusion that Mag Uidhir reaches, I believe, does not at all follow from the premises he proposes.

Mag Uidhir wants to demonstrate that art and pornography are radically separate categories by showing that the success conditions for both categories are fundamentally different. Premise (4) specifies that, for something to count as a sexually arousing work of art, i.e., a work of art that fulfils its purpose of bringing about sexual arousal, it needs to bring about sexual arousal in the prescribed way. Premise (2), by contrast, states that for something to count as a successful work of pornography, i.e., a work of pornography that fulfils its purpose, it needs to bring about sexual arousal, period. In Mag Uidhir's own words, the "sexual arousal of the audience simpliciter matters. . . This is precisely what it means to be manner inspecific" (p. 197). If, for argument's sake, we accept these premises to be true (which, to my mind, is not obviously the case ${ }^{6}$ ), then we have established that there is an important difference between the category of art and the category of pornography. What has not been shown, however, is that both categories are mutually exclusive.

In order to show that something cannot legitimately fall under both categories, it is simply not enough to argue that their respective success conditions are different. One needs to show that it is impossible for a particular object to fulfil both success conditions. And Mag Uidhir's argument does not do that. Not only is it perfectly possible for a particular work to satisfy both success conditions, but satisfying the success conditions for sexually arousing art even seems to entail satisfying the stated success conditions for pornography. For suppose that a novel, a photograph or a film brings about sexual arousal in the prescribed way (and we can take this to mean whatever Mag Uidhir wants it to mean). Then it will have fulfilled the success condition for sexually arousing art ("for something to count as a sexually arousing work of art, it needs to brings about sexual arousal in the prescribed way") as well as the success condition for pornography ("for something to count as a successful work of pornography it needs to bring about sexual arousal, period”).

Note that the latter thought does not imply that each sexually arousing work of art is automatically a work of pornography since Mag Uidhir 
only refers to necessary, not sufficient, conditions for something's being pornography or (sexually arousing) art. However, it does cut away the ground under the idea of a sharp division between pornography and art, with no chance of overlap. Contrary to Mag Uidhir's confident conclusion, we have no a priori reason to assume that if something is pornography it cannot be art.

In a sense, this outcome is not just reassuring for the advocates of pornographic art. If Mag Uidhir's argument had been successful it would have been very easy to construct similar arguments showing how nothing can be both a piece of furniture and a work of art, or a religious mask and a work of art, or journalism and art, etc. Here is one example of how this would work. (All remaining doubts about the invalidity of the argument will surely disappear if one keeps Cellini's magnificent Saliera in mind.)

(1) If something is a salt cellar, then that something has the purpose of holding and dispensing salt.

(2) If something is a salt cellar, then that something has the purpose of holding and dispensing salt and that purpose is manner inspecific.

(3) If something is art, then if that something has a purpose, then that purpose is manner specific.

(4) If something is art, then if that something has the purpose of holding and dispensing salt, then that purpose is manner specific.

(5) A purpose cannot be both manner specific and manner inspecific.

(6) Therefore, if something is a salt cellar, then it is not art.

This argument fails for the exact same reason that the pornography argument fails. The fact that Mag Uidhir's approach, applied consistently, would force us to exclude much uncontentious art from the realm of art (the decorated urns of ancient Greece, nineteenth-century dance music, didactic novels, religious icons) I consider it to be just another nail in the coffin for his view.

\section{III}

Pornographic art is not the oxymoron that Levinson and Mag Uidhir assume it to be. Of course, there may be other arguments against the 
possibility of pornographic art that I haven't considered yet. But I am confident that these, too, will prove to be invalid or unsound when examined closely. Here is why: I am sure that there can be works of pornographic art, simply because there already are works of pornographic art. Let me list a few examples taken from different art forms.

In the domain of literature one could mention, besides the inevitable Marquis de Sade, Pierre Louÿs's Trois Filles de Leur Mère (She-Devils), Pauline Réage's Histoire d'O (The Story of O), and Mieke Maaike's Obscene Jeugd (The Obscene Youth of Mieke Maaike), written by one of Flanders' most celebrated authors, Louis Paul Boon. In the visual arts there is the rich tradition of Japanese shunga illustrations: woodblock prints depicting sexually explicit scenes intended for use in brothels and the private bedroom. Exquisite examples include Hishikawa Morohira's "Erotic scenes" (c. 1700), Isoda Koryusai's "Man kissing woman's nipple" (late eighteenth century), Kitagawa Utamaro's "Woman with man with black cloth and food service" (1788) and Katsushika Hokusai's famous depiction of an Awabi fisherwoman being "embraced" by an octopus ("Untitled" 1824). Indian culture gave us the Kama Sutra and many highly artistic miniatures depicting sexual positions directly or indirectly inspired by the Kama Sutra. "The private pleasure of Prince Murad son of Shah Jahah by Goverdhan" or "The private pleasure of Raja Dalpat Singh by Lakroo" (1678-98) are just two examples. In the Western tradition there are a number of canonized artists who have produced paintings, drawings, engravings of an unmistakable pornographic nature (though for censorship reasons these were rarely displayed in public and often deliberately kept secret). Images such as "Reclining Masturbating Girl" by Klimt (1916-17), "Woman with Black Stockings" (1913) by Schiele, "Female Nude on All Fours, Rear View, Dress Lifted to Hips" by Rodin (undated), or "I Modi" created by the engraver Marcantonio Raimondi after a series of paintings by Giulio Romano (16th century), are as explicit and arousing as any image in Hustler Magazine, though their artistic quality is infinitely greater. When arguing for the existence of pornographic art photography the obvious name to mention is Robert Mapplethorpe, while In the Realm of the Senses (Nagisa Ôshima, 1976), with its many subtle references to the shunga tradition, is often cited as the best example of a pornographic art film. Finally, there is the artform of the graphic novel, often overlooked in discussions about pornographic art. There are numerous pornographic comic books that, in my opinion, deserve the status of art, including (but not limited to): Guido Crepax's “The Story of O” (1975) and "Justine” (1979), Alan 
Moore and Melinda Gebbie's "Lost Girls" (2006), and Dave McKean's short story "X-Rated" (2009). This by no means exhaustive list indicates that the cross-section between pornography and art does not just exist in theory but in reality. The label "pornographic art" seems perfectly appropriate for each one of the examples mentioned.

It should be said that both Levinson and Mag Uidhir have tried to anticipate and neutralize possible counterexamples. In fact, both have argued that the phrase "pornographic art" can be used in a meaningful way, without thereby conceding that there is an extensional overlap of pornography and art. Nevertheless, their respective "escape strategies" have considerable weaknesses and, as I will now show, prove ineffective against the examples I have just listed.

\section{IV}

To remove the air of paradox from the assertion that there is pornographic art but nothing that is both art and pornography, Levinson appeals to a weak and a strong sense of the term "pornographic": "In the strong, or conjunctive, sense, something is pornographic art if it is both art and pornography; in the weak, or modifying, sense, something is pornographic art if it is art and has a pornographic character, look, or aspect" (p. 235). To clarify this distinction he draws an analogy with photographic art. When we call something "photographic art" this usually means that the object is both a photograph and art. But that is not always the case. Think of the photorealist paintings of Chuck Close or Richard Estes. These are often termed "photographic art" though they are not photographs. The term "photographic" is used here in the weak, modifying sense. According to Levinson, there is only pornographic art in the weak sense of "pornographic": works of art that are copying the look of pornography or using cutouts from pornographic magazines or that contain allusions to pornography, without themselves actually being pornography.

When the popular media use the expression "pornographic art" it is indeed often to refer to the kind of work that Levinson has in mind. Chris Ofili's "The Holy Virgin Mary" (1996), which caused quite a media uproar, is one example. One could also think of some of Thomas Ruff's nude photographs, Jeff Koons's statuettes, Marlene Dumas's paintings, Fiona Banner's text pieces, Paul McCarthy's inflatables, or Ghada Amer's embroidery. Such works are directly inspired by pornography and have been condemned (and sometimes praised) as "pornographic art," but 
they are not pornography. For one thing, they are not centrally aimed at sexual arousal and, as almost all theorists will agree, this is a necessary condition for something's being pornography. So, these works lack an essential feature of pornography, just like one or more essential features of photography are missing from Estes's and Close's paintings.

However, while the pornographic artworks of Ofili, Dumas or Amer can usefully be excluded from the realm of pornography and hence do not qualify as both art and pornography, the same is not true of the examples of pornographic art that I have put forward. All the works mentioned in section III are centrally aimed at bringing about sexual arousal. ${ }^{7}$ So, these works provide counterexamples to Levinson's account that cannot be set aside by appealing to a weak sense of the word "pornographic." Unsurprisingly, most of them are ignored in Levinson's text.

Of all the works listed in section III, Levinson only mentions the drawings of Klimt and Schiele as potential problems for his account. The latter's work in particular raises his concern as "Schiele's manifest intention for many of his sexually-themed drawings was indeed pornographic, since they were created expressly for male patrons with precisely that sort of use in mind" (p. 238). He sees two ways of dealing with this case (without expressing a clear preference for one solution over the other): "The first is simply to accept that, on the conception defended here, those drawings must be accounted pornography, but pornography that it is uncommonly aesthetically rewarding. ... The second is to posit for those drawings an implicit artistic intention as robust as the explicit pornographic one ... in virtue of which they can be accounted, though uneasily, erotic art after all” (p. 238).

Both suggested solutions are deeply unsatisfactory. The first proposal is to put Schiele's sexually-themed work squarely in the category of "pornography" and deny it the status of "art." While Levinson may be willing to bite this bullet, art critics or art historians will find this completely unacceptable. The second proposal is to think of the work as the product of two equally robust intentions: an artistic and a pornographic one. But that such a thing could be possible is exactly what Levinson's whole argument is meant to disprove. His account is built entirely on the idea that the two intentions war against one another (which brings to mind J. L. Austin's famous quip about the ways of philosophers: "There's the bit where he says it and the bit where he takes it back").

I think it is more than appropriate to call Schiele's art "pornographic" in the strong sense of the term and I believe the same holds true for the other examples I mentioned in section III. Each of these works qualifies 
as both art and pornography. I am by no means the only one who thinks so. Linda Williams, for instance, calls In the Realm of the Senses "the first example of feature-length narrative cinema anywhere in the world to succeed as both art and pornography." 8 Arthur Danto underlines the fact that Mapplethorpe "achieves images that are beautiful and exciting at once: pornography and art in the same striking photographs." Douglas Wolk says of Lost Girls: "It is . . beautiful, literary and moving. It's also bluntly pornographic, with explicit sex scenes on almost every page." ${ }^{10}$ After reading Pauline Réage's The Story of O Susan Sontag was convinced that "works of pornography can belong to literature" 11 and Brian Aldiss wrote: "I do believe that Pauline Réage has confounded all her critics and made pornography . . an art."12

These examples of pornographic art, I now want to argue, also undermine Mag Uidhir's account. Mag Uidhir basically agrees with Levinson that when a picture or novel is labeled "pornographic art" this only means "that the artwork is like pornography, that is, displays characteristics typical of actualworld pornography—being sexually explicit, indecent, obscene, even objectifying or degrading" (Mag Uidhir, pp. 200-201). A pornographic work of art, he thinks, is not both a work of art and pornography. By contrast, a pornographic magazine is both a magazine and pornography. Unlike Levinson, Mag Uidhir does not appeal to a strong and a weak sense of the term "pornographic" to explain this distinction. Rather, he thinks that the word performs two different functions in the expressions "pornographic magazine" and "pornographic art." The word is used "first to indicate what purpose the thing has or what features the thing was intended to have and second to indicate what (salient) features the thing in fact has or doesn't have" (p. 201).

To demonstrate that this is indeed the case, he asks us to consider the sentence "This pornographic art is decidedly unpornographic." Such a sentence sounds awkward in the same way that the sentence "This romantic gesture is decidedly unromantic" sounds awkward. Both sentences are odd, he explains, because they tell us that their respective things both have and do not have certain features-which is nonsensical. By comparison, the sentence "This pornographic magazine is decidedly unpornographic" does not sound awkward at all, just like there is nothing odd about saying "This romantic comedy is decidedly unromantic." The latter two sentences simply tell us that while their respective things were intended to have certain features they do not as a matter of fact have those features.

The first critical question one could ask is this: if the distinction 
between "pornographic art" and "pornographic magazine" really runs parallel to the distinction between "romantic gesture" and "romantic comedy," and if the word "romantic" in "romantic comedy" only indicates that the comedy is intended to be romantic, whereas the same word in the phrase "romantic gesture" indicates that the gesture is actually romantic, then shouldn't we conclude that the word "pornographic" in "pornographic art" indicates that it is actually, genuinely pornographic whereas the same word in "pornographic magazine" performs no such function? This would be the exact opposite of the conclusion Mag Uidhir wants to reach.

I admit that it would be a little too easy to dismiss the argument on the basis of this somewhat uncharitable reading alone. Mag Uidhir's point, I take it, is that while a pornographic magazine is made explicitly with the purpose of being pornography, a pornographic work of art is not and that this makes all the difference. Pornographic works of art may possess various salient features of pornography but they are not created for pornographic use and hence do not qualify as pornography. However, taken as a factual statement, this is simply wrong. As I have indicated above, all the works listed in section III were created, at least partly, for pornographic purposes. Moreover, to infer from the awkwardness of "This pornographic art is decidedly unpornographic" that nothing can be both art and pornography - which, in a sense, is what Mag Uidhir's argument boils down to-is highly problematic. Just think of the equally awkward statement "This photographic art is decidedly unphotographic." Surely, one would not want to infer from this that nothing can be both art and photography? Relatedly, and most crucially, even if statements like "This pornographic art is decidedly unpornographic" or "This photographic art is decidedly unphotographic" sound a little odd, that does not mean that one cannot think of a context in which such statements would make perfect sense. Consider "painterly photography" as practiced by some contemporary photographers. These photographs look so much like paintings that one would not at all be surprised to hear someone say "This photographic art is decidedly unphotographic." Similarly, it is not that difficult to think of a context in which it would be appropriate to say of a pornographic work of art that it is "decidedly unpornographic." For instance, several critics have pointed out that, in contrast to cliché instances of pornography, Lost Girls is not one-dimensional, unimaginative, or anti-intellectual. In that respect, one could say that the pornographic work of Alan Moore and Melinda Gebbie is decidedly unpornographic. Or take the short film 
Skin (Elin Magnusson, 2009). Contrary to what one might expect from a pornographic film, Skin is not objectifying, loveless, exploitative or aggressive. As such, it would not be awkward to call this pornographic work of art "decidedly unpornographic." In effect, it is very easy to set up a similar construction for all of the examples of pornographic art that I have put forward. That is precisely because, as works of pornography, they are all untypical ("unpornographic") in the sense that they were created by artists who succeeded in avoiding the low aesthetic standards of the average pornographic product and thus, pace Mag Uidhir and Levinson, in creating art.

At present, the collection of works that qualify as both pornography and art only constitutes a tiny subclass of the domain of pornography. This is hardly surprising given, on the one hand, the vast output of the porn industry and, on the other hand, the various legal, political, moral, and economical restrictions that still make it difficult for established artists and filmmakers to properly engage with this material. However, while the cross-section of art and pornography may be small in size, I have tried to show that it is not non-existent. And I wish to conclude by expressing the hope that in the future there will be more novels, photographs, comic books, and movies that will confidently occupy this interesting middle ground. After all, as a famous film critic once put it, "sex is too important to be left to the sex-film industry." 13

UNIVERSITY OF KeNT

I wish to thank Peter Brems, Rafael De Clercq, Andrew Kania, Jerrold Levinson, Paisley Livingston, and Katrien Schaubroeck for their valuable input on earlier versions of this paper.

1. Jerrold Levinson, "Erotic Art and Pornographic Pictures," Philosophy and Literature 29 (2005): 228-40.

2. Hans Maes, "Art and Pornography," Journal of Aesthetic Education 43 (2009): 107-16.

3. Roger Ebert, Movie Yearbook 2009 (Kansas City: McNeel, 2009), pp. 65-66.

4. Roger Ebert, The Great Movies (New York: Broadway Books, 2002), pp. 282-83.

5. Christy Mag Uidhir, "Why Pornography Can't Be Art," Philosophy and Literature 33 (2009): 193-203. 
6. Premise 3 is especially dubious. Works of art can have many purposes and it seems to me that not all of these purposes have to be manner specific.

7. Arthur Danto, in his authoritative study Playing with the Edge: The Photographic Achievement of Robert Mapplethorpe, observes that the photographer's ambition "was to create images that would be as arousing as those in porn magazines, but artistic: to achieve 'smut that is also art'" (Berkeley: University of California Press, 1995). For similar comments regarding the work of Nagisa Ôshima and Alan Moore, see respectively Linda Williams, Screening Sex (Durham: Duke University Press, 2008) and Erotic Comics: A Graphic History, vol. 3, ed. Tim Pilcher (Cambridge: ILEX, 2008).

8. Williams, p. 183. She also calls it "a form of hard-core art pioneered by such respected artists as Utamaro Kitagawa, Hokusai Katshushika, and Harunobi Suzuki” (p. 184).

9. Arthur C. Danto, The Abuse of Beauty: Aesthetics and the Concept of Art (Chicago: Open Court, 2003), p. 82.

10. Douglas Wolk, "Alan Moore's 'Literary' Pornography," Publishers Weekly (Jan. 5, 2006).

11. Susan Sontag, "The Pornographic Imagination," in Styles of Radical Will (London: Vintage, 1994), p. 44.

12. As quoted on the cover of the Erotic Classic edition of the book (London: Corgi Books, 1972).

13. Richard Corliss, "In Defense of Dirty Movies," Time Magazine (July 5, 1999). 